\title{
BMJ Open A cross-sectional study of the prevalence, awareness, treatment and control of hypertension in Shenzhen, China
}

\author{
Haitao Li, ${ }^{1}$ Xinfeng Yan, ${ }^{2}$ Xiaoting Deng, ${ }^{2}$ Lizhen $Y a n g,{ }^{2}$ Shaojuan Zhao, ${ }^{2}$ \\ Jianfeng Zou, ${ }^{2} \mathrm{Yi} \mathrm{Luo,}^{2}$ Sijing CaO ${ }^{2}$
}

To cite: Li H, Yan X, Deng X, et al. A cross-sectional study of the prevalence, awareness, treatment and control of hypertension in Shenzhen, China. BMJ Open 2017;7:e015206. doi:10.1136/ bmjopen-2016-015206

- Prepublication history for this paper is available online. To view these files please visit the journal online (http://dx.doi. org/10.1136/bmjopen-2016015206).

$\mathrm{HL}$ and $\mathrm{XY}$ contributed equally.

Received 18 November 2016 Revised 20 April 2017 Accepted 2 May 2017

\section{CrossMark}

${ }^{1}$ School of Medicine, Shenzhen University, Shenzhen, China ${ }^{2}$ Longhua District Center for Chronic Disease Prevention and Control, Shenzhen, China

Correspondence to Dr Haitao Li; htli1223@szu. edu.cn

\section{ABSTRACT}

Objectives An understanding of the awareness, treatment and control of hypertension is helpful to guide decisionmaking regarding interventions to reduce the risk for diseases with hypertension as a key risk factor. This study aimed to estimate the prevalence, awareness, treatment, and control of hypertension in Shenzhen, China. Methods A cross-sectional study was conducted. We employed multistage cluster random sampling methods to select participants. A survey involving face-to-face interviews was conducted to collect the data. A total of 1676 participants finished the survey and formed the final analysis.

Results We found that the prevalence of hypertension was $17.6 \%$. The rates of hypertension awareness, treatment and control were $48.8 \%, 51.4 \%$ and $43.2 \%$ respectively. Only $6.8 \%$ hypertensives were found to be managed by community health centres. Compared with the female participants, the males were found to have higher rates of prevalence (19.7\% vs $15.7 \%$; OR $1.47,95 \% \mathrm{Cl} 1.10$ to 1.97$)$ and awareness (42.9\% vs $38.1 \%$; OR $2.35,95 \% \mathrm{Cl} 1.28$ to 4.33 ), but lower rates of medication treatments $(20.5 \%$ vs $30.2 \%$; OR $0.83,95 \% \mathrm{Cl}$ 0.05 to 0.92$)$ and control ( $12.8 \%$ vs $23.0 \%$; OR $0.45,95 \%$ $\mathrm{Cl} 0.21$ to 0.96$)$. Migrants were more likely to be aware of hypertension (32.5\% vs $44.3 \%$; OR $0.57,95 \% \mathrm{Cl} 0.30$ to $0.90)$, reduce their salt intake ( $8.8 \%$ vs $18.1 \%$; OR 0.40 , $95 \% \mathrm{Cl} 0.15$ to 0.94$)$, and undertake regular monitoring of hypertension (1.3\% vs $11.0 \%$; OR $0.14,95 \% \mathrm{Cl} 0.02$ to 0.92) when compared with the locals.

Conclusions Our study finds that hypertension is an important public health burden in Shenzhen. It implies that strategies need to be developed to improve effective primary care management of hypertension. It also suggests a need to develop gender and household register tailored strategies for the prevention, detection, treatment and control of hypertension.

\section{BACKGROUND}

Cardiovascular disease (CVD) is a major cause of death and a major contributor to the world's global disease burden, including China. Statistics showed that CVD caused about 17 million deaths $(31.5 \%)$ in 2013 globally, and that $>80 \%$ occurred in

\section{Strengths and limitations of this study}

A rigorous random sampling approach was adopted and implemented in this large scale representative study.

- With standard protocols and instruments, data were collected by extensively trained interviewers and supervised by a vigorous quality assurance programme.

- We followed the most commonly used international definition of prevalence, awareness, treatment and control of hypertension to facilitate compatibility with the international literature.

- Data on awareness, pharmacological and nonpharmacological treatments, and primary care management relied on self-report.

- Diagnosis of hypertension was based on a single visit involving blood pressure measurements and history recall.

low- and middle-income countries. ${ }^{1}$ In China, one-third of all deaths were estimated to be due to CVD in $2005,{ }^{2}$ and it is anticipated that CVD events will have increased by $23 \%$ by $2030 .^{3}$

Hypertension is a major modifiable CVD risk factor. The risk for CVD doubles with each increment of $20 \mathrm{~mm} \mathrm{Hg}$ in systolic blood pressure (SBP), or $10 \mathrm{~mm} \mathrm{Hg}$ in diastolic blood pressure (DBP). ${ }^{4}$ According to the World Health Statistics 2012 report, one in three adults had elevated blood pressure worldwide. ${ }^{5}$ It has been projected that, in 2025 , there will be 1.56 billion adults living with hypertension globally. ${ }^{6}$ As with other developing countries, the prevalence of hypertension in the Chinese population increased sharply from $5.1 \%$ in $1959^{7}$ to $7.7 \%$ in $1979,{ }^{8}$ and escalated from $11.9 \%$ in $1991^{9}$ to $18.8 \%$ in $2002 .{ }^{10}$ Therefore, hypertension control is important for reducing the risk for CVD and other diseases with hypertension as a key risk factor. 
Investigators studying the extent and determinants of hypertension control have found it useful to divide hypertensive individuals into subgroups based on the individuals' awareness, treatment, and control of hypertension. This categorization, emanating from the necessary steps in hypertension, has been used to guide decision-making regarding interventions. The current study aimed to provide an updated estimate of prevalence, awareness, treatment, and control of hypertension in Shenzhen, China. This study is expected to have an impact on public policy for better hypertension control, and to have implications for policymakers worldwide with social and cultural contexts similar to those of Shenzhen, China.

\section{METHODS}

\section{Study setting}

Shenzhen is located in the Pearl River Delta region of southern China. It is China's first Special Economic Zone holding sub-provincial administrative status. It is divided into 10 district-level jurisdictions. The total area of Shenzhen is 1996.8 square kilometres. According to the statistics for 2014, Shenzhen's population is around 10.78 million with about $70 \%$ being migrants. ${ }^{11}$ Shenzhen is a major financial centre in southern China, and the largest manufacturing base in the world. In 2010, the total gross domestic product (GDP) of Shenzhen was RMB 0.96 trillion with GDP per capita of RMB91823. ${ }^{11}$

\section{Study population and procedures}

This large cross-sectional study was conducted between April and May 2015 in Shenzhen, China. The study population comprised all community residents who (1) had been living in Shenzhen $\geq 6$ months, (2) were aged 18 to 70 years old, and (3) were able to participate in the study and give informed consent. We excluded the residents living in military posts, students' dormitories, nursing homes and bunkhouses. We employed the multistage cluster random sampling method to select participants. First, two of 10 districts (primary sampling units) were selected using a simple random sampling approach (ie, district A and B). Second, 10 neighbourhoods (secondary sampling units) were randomly drawn from each randomly selected district. Third, households (tertiary sampling units) were sampled employing a systematic random sampling approach within each neighbourhood on the basis of a household roster. According to the population of each district, we selected a total of 600 households within district A and 1400 within district B. Sixty households per neighbourhood in district A were randomly selected, while 140 were randomly selected for district B. A Kish method was deployed for participant selection within each household. A survey was conducted involving face-to-face interviews at the participants' homes by extensively trained interviewers. Blood pressure measurements were performed by nurses. The participants were assured of the anonymity and confidentiality of the survey, and informed consent was obtained before the survey started. A total of 1784 residents, with 538 from district A and 1246 from district B, finished the survey, with a response rate of $89.0 \%$ and $89.7 \%$, respectively.

\section{Key measures}

Using a calibrated mercury sphygmomanometer, the blood pressure of participants was measured according to the protocol recommended by the national guidelines for hypertension management. ${ }^{12}$ Before the blood pressure measurements were taken, the participants were seated with their backs supported and their legs resting on the floor for at least $5 \mathrm{~min}$. They needed to have refrained from cigarette smoking and drinking caffeinated beverages for at least $30 \mathrm{~min}$ before measurement. The arm of the participant used for measurement was positioned at the same level as the heart. Two measurements were conducted with an interval of 1-2 min. SBP and DBP were recorded as the means of two measurements. If the difference between the two measurements was $>5 \mathrm{mmHg}$, an additional measurement would be performed and the mean of all three measurements would be recorded. Hypertension was defined as a self-reported physician-diagnosed condition currently under antihypertensive treatment, and/or SBP $\geq 140 \mathrm{~mm} \mathrm{Hg}$ and/or DBP $\geq 90 \mathrm{~mm} \mathrm{Hg}$. The prevalence of hypertension was then calculated. Awareness of hypertension was defined as a self-report of any previously diagnosed hypertension by health professionals. Treatment information including both pharmacological and non-pharmacological management of hypertension was self-reported. The participants were asked: (1) 'whether they reduced intake of salt' (yes or no); (2) 'whether they did regular physical exercise for the management of hypertension' (yes or no); (3) 'whether they were under regular monitoring to control the disease' (yes or no); and (4) 'whether they were using antihypertensive medication' (yes or no). The participants were also asked 'whether they were under primary care management in community health centres' (yes or no). Hypertension control was defined as a blood pressure $<140 / 90 \mathrm{~mm} \mathrm{Hg}$.

Sociodemographic characteristics of the participants were collected including gender, age, marital status, household register, education level, occupation, and monthly household income. Marital status was categorised into three groups, including individuals never in union, individuals married or living with partner, as well as individuals widowed, divorced and separated. We classified the participants into local and migrant residents according to the household register. Migrants refer to individuals who have moved to a new location without changing their official household registration. ${ }^{13}$ Education level was grouped into four categories: primary school and below, middle school, high school and equivalent, and 3 year college and above. The participants were allocated into six groups according to occupation, including manual workers, sales and services, clerical, other workers, unemployed, and professional, technical and managerial. The 
monthly household income was divided into three groups according to monthly household poverty line (RMB 5000) and mean monthly household income level (RMB10000) in Shenzhen in 2011. ${ }^{14}$

\section{Statistical analyses}

All collected data were inputted into the EpiData 3.1 database. All descriptive statistics were presented regarding the participants' sociodemographic characteristics (ie, age, gender, marital status, education level, household register, occupation, monthly household income, and blood pressure values), as well as prevalence, awareness, management, treatment and control of hypertension. Comparisons with respect to prevalence, awareness, management, treatment and control of hypertension were made between male and female participants, as well as between local and migrant participants, by using $\chi^{2}$ tests. Multiple logistic regression models were constructed for comparisons after controlling for the participants' sociodemographic characteristics (including gender, age, marital status, education level, household register, occupation, and monthly household income). All of the covariates in the multiple logistic regression models were categorical. OR and $95 \%$ CI were provided. For all analyses conducted in the study, $\mathrm{p}<0.05$ was considered to be statistically significant. All analyses were performed using SPSS19.0 (IBM, USA).

\section{RESULTS}

One participant with missing information on blood pressure values was excluded from the analysis. Thus, a total of 1676 participants formed the final analysis. The average age was 39.26 years and a higher proportion $(52.8 \%)$ was female. The majority of the participants were married or living with their partner $(88.1 \%)$. Most of the participants had an eductional level of middle school $(36.0 \%)$ or high school and equivalent $(31.5 \%)$. More than a quarter of the participants $(27.2 \%)$ were unemployed when the survey was conducted. Migrants accounted for $72.6 \%$ of the participants, with the remainder being from the local area $(26.4 \%)$. Approximately $36.2 \%$ of the participants were in the middle income group, while around one third refused to indicate $(10.3 \%)$ or did not know $(22.8 \%)$ their monthly household income. The average SBP of the participants was $119.81 \mathrm{~mm} \mathrm{Hg}$, while the average DBP was $77.63 \mathrm{~mm} \mathrm{Hg}$ (table 1).

The overall prevalence of hypertension was $17.6 \%$ $(295 / 1676)$. Of all the individuals with hypertension, $48.8 \%$ (144/295) were aware of their condition. Among all the hypertensive individuals, $25.1 \%$ (74/295) were using antihypertensive medications, while the percentage among hypertensive individuals who were aware of their condition was $51.4 \%(74 / 144)$. The percentages of all hypertensive individuals who adopted non-pharmacological treatment was $15.6 \%(46 / 295)$ for reduced salt intake, and $11.2 \%$ (33/295) for regular physical exercise. Only $8.1 \%(24 / 295)$ of all hypertensive individuals
Table 1 Characteristics of participants $(n=1676)$

\begin{tabular}{|c|c|}
\hline Characteristics & n (\%) \\
\hline Age, years (mean, SD) & $39.26(11.13)$ \\
\hline $18-44$ & $1179(70.3)$ \\
\hline $45-59$ & 392 (23.4) \\
\hline$\geq 60$ & $103(6.1)$ \\
\hline \multicolumn{2}{|l|}{ Gender } \\
\hline Male & $791(47.2)$ \\
\hline Female & $885(52.8)$ \\
\hline \multicolumn{2}{|l|}{ Education } \\
\hline Primary school and below & $231(13.8)$ \\
\hline Middle school & $603(36.0)$ \\
\hline High school and equivalent & $528(31.5)$ \\
\hline 3 year college and above & 306 (18.3) \\
\hline \multicolumn{2}{|l|}{ Marital status } \\
\hline Never in union & $149(8.9)$ \\
\hline Married and living with partner & $1476(88.1)$ \\
\hline Widowed, divorced and separated & $42(2.5)$ \\
\hline \multicolumn{2}{|l|}{ Occupation } \\
\hline Manual workers & $253(15.1)$ \\
\hline Sales and services & $320(19.1)$ \\
\hline Professional technical and managerial & $214(12.8)$ \\
\hline Clerical & $176(10.5)$ \\
\hline Other workers & $251(15.0)$ \\
\hline Unemployed & $456(27.2)$ \\
\hline \multicolumn{2}{|l|}{ Registration } \\
\hline Locals & $442(26.4)$ \\
\hline Migrants & $1216(72.6)$ \\
\hline \multicolumn{2}{|l|}{ Household income } \\
\hline Low & $170(10.1)$ \\
\hline Middle & $606(36.2)$ \\
\hline High & $346(20.6)$ \\
\hline Rejected & $172(10.3)$ \\
\hline Do not know & $382(22.8)$ \\
\hline Systolic blood pressure (mean, SD) & $119.81(15.65)$ \\
\hline Diastolic blood pressure (mean, SD) & $77.63(10.79)$ \\
\hline Hypertension & $295(17.6)$ \\
\hline
\end{tabular}

were monitored regularly, while only $6.8 \%(20 / 295)$ were under management by community health centres. It was found that $17.6 \%(52 / 295)$ of all hypertensive individuals had their blood pressure under control, while the hypertension control rate was $43.2 \%$ (32/74) among hypertensive individuals who were under antihypertensive medication treatment (table 2).

After adjustments were made for sociodemographic characteristics of the participants, the results showed that the hypertension prevalence rate was higher in male participants than in their female counterparts $(19.7 \%$ vs 
Table 2 Prevalence, awareness, treatment and control of hypertension

\begin{tabular}{lllll}
\hline Variables & Absolute numbers & $\begin{array}{l}\text { Among all } \\
\text { hypertensives, \% }\end{array}$ & $\begin{array}{l}\text { Among aware } \\
\text { hypertensives, \% }\end{array}$ & $\begin{array}{l}\text { Among hypertensives under } \\
\text { drug treatment, } \mathbf{n}(\%)\end{array}$ \\
\hline Prevalence & 295 & 100.0 & - & - \\
Awareness & 144 & 48.8 & 100.0 & - \\
Treatment & & & - \\
Antihypertensive medications & 74 & 25.1 & 51.4 & - \\
Reduced salt intake & 46 & 15.6 & 31.9 & - \\
Regular physical exercise & 33 & 11.2 & 22.9 & - \\
Regular monitoring & 24 & 8.1 & 16.7 & - \\
$\begin{array}{l}\text { Under primary care } \\
\text { management }\end{array}$ & 20 & 6.8 & 13.9 & - \\
\begin{tabular}{l} 
Control \\
\hline
\end{tabular} & 52 & 17.6 & 36.1 & $32(43.2)$ \\
\hline
\end{tabular}

$15.7 \%$; OR $1.47,95 \%$ CI 1.10 to 1.97$)$. Meanwhile, more male participants were aware of their condition than female participants $(42.9 \%$ vs $38.1 \%$; OR 2.35 , $95 \%$ CI 1.28 to 4.33$)$. Female participants were more likely to utilise antihypertensive medications $(20.5 \%$ vs $30.2 \%$; OR $0.83,95 \%$ CI 0.05 to 0.92 ), but less likely to undertake regular physical exercise $(14.7 \%$ vs $6.5 \%$; OR $4.79,95 \%$ CI 1.67 to 13.74 ) when compared with male participants. The hypertension control rate was found to be higher in female than in male participants $(12.8 \%$ vs $23.0 \%$; OR $0.45,95 \%$ CI 0.21 to 0.96 ) (table 3 ).
Further analyses were conducted to explore the differences between local and migrant participants. We found that the awareness rate was significantly higher in the migrants than in the locals $(32.5 \%$ vs $44.3 \%$; OR 0.57 , $95 \%$ CI 0.30 to 0.90$)$. Moreover, compared with the locals, migrant participants were more likely to undertake non-pharmacological treatments including reduced salt intake $(8.8 \%$ vs $18.1 \%$; OR $0.40,95 \%$ CI 0.15 to 0.94$)$ and regular monitoring of hypertension $(1.3 \%$ vs $11.0 \%$; OR $0.14,95 \%$ CI 0.02 to 0.92 ) (table 3 ).

Table 3 Prevalence, awareness, treatment and control of hypertension by gender and household register

\begin{tabular}{|c|c|c|c|c|c|c|}
\hline \multirow[b]{2}{*}{ Variables } & \multicolumn{3}{|l|}{ Gender } & \multicolumn{3}{|c|}{ Household register } \\
\hline & Males, n (\%) & $\begin{array}{l}\text { Females, } \\
\text { n }(\%)^{*}\end{array}$ & OR $(95 \% \mathrm{Cl})^{\dagger}$ & Locals, n (\%) & $\begin{array}{l}\text { Migrants, } \\
\mathrm{n}(\%)^{\star}\end{array}$ & OR $(95 \% \mathrm{Cl})^{\dagger}$ \\
\hline Prevalence & $156(19.7)$ & $139(15.7)^{\ddagger}$ & 1.47 (1.10 to 1.97$)$ & $80(18.1)$ & $210(17.3)$ & $\begin{array}{l}1.00 \\
(0.72 \text { to } 1.40)\end{array}$ \\
\hline Awareness & 67 (42.9) & $53(38.1)$ & 2.35 (1.28 to 4.33 ) & $26(32.5)$ & $93(44.3)^{\ddagger}$ & $\begin{array}{l}0.57 \\
(0.30 \text { to } 0.90)\end{array}$ \\
\hline \multicolumn{7}{|l|}{ Treatment } \\
\hline $\begin{array}{l}\text { Antihypertensive } \\
\text { medications }\end{array}$ & $32(20.5)$ & $42(30.2)^{\ddagger}$ & $\mathbf{0 . 8 3}$ (0.05 to 0.92$)$ & $15(18.8)$ & $57(27.1)$ & $\begin{array}{l}0.65 \\
(0.30 \text { to } 1.40)\end{array}$ \\
\hline Reduced salt intake & $25(16.0)$ & $21(15.1)$ & 1.69 (0.77 to 3.73$)$ & $7(8.8)$ & $38(18.1)^{\ddagger}$ & $\begin{array}{l}0.40 \\
(0.15 \text { to } 0.94)\end{array}$ \\
\hline Regular physical exercise & $23(14.7)$ & $9(6.5)^{\ddagger}$ & 4.79 (1.67 to 13.74$)$ & $9(11.3)$ & $22(10.5)$ & $\begin{array}{l}0.66 \\
(0.25 \text { to } 1.80)\end{array}$ \\
\hline Regular monitoring & $11(7.1)$ & $13(9.4)$ & 0.86 (0.29 to 2.54$)$ & $1(1.3)$ & $23(11.0)^{\S}$ & $\begin{array}{l}0.14 \\
(0.02 \text { to } 0.92)\end{array}$ \\
\hline $\begin{array}{l}\text { Under primary care } \\
\text { management }\end{array}$ & $9(5.8)$ & $11(7.9)$ & 0.69 (0.23 to 2.08$)$ & $7(8.8)$ & $13(6.2)$ & $\begin{array}{l}1.98 \\
(0.64 \text { to } 6.12)\end{array}$ \\
\hline Control & 20 (12.8) & $32(23.0)$ & 0.45 (0.21 to 0.96$)$ & $17(21.3)$ & $34(16.2)$ & $\begin{array}{l}1.33 \\
\text { (0.61 to } 2.89)\end{array}$ \\
\hline
\end{tabular}

${ }^{*} \chi^{2}$ tests were used for comparisons.

†Multiple logistic regression analyses adjusted for the participants' gender, age, marital status, education level, household register, occupation, and monthly household income (the female participants and the migrants were the reference groups). $\neq \mathrm{p}<0.05$. $\S \mathrm{p}<0.01$. 


\section{DISCUSSION}

The present study investigated the prevalence, awareness, treatment and control of hypertension in a large representative sample in Shenzhen, China. We found that hypertension is an important public health burden, with a prevalence of $17.6 \%$. The rates of hypertension awareness, treatment and control found in this study were $48.8 \%, 51.4 \%$ and $43.2 \%$, respectively. However, less than 1 in 10 of the hypertensive individuals were managed by community health centres. This study found a large gap between male and female hypertensive individuals, as well as between migrants and the locals, in at least one of the categories of hypertension prevalence, awareness, treatment and control.

The results showed that the prevalence of hypertension was $17.6 \%$ among Shenzhen residents aged between 18 and 69 years. Our current estimate is lower than that at the national and international level, which may be due to the younger average age of Shenzhen residents. A report by WHO showed that the global prevalence of hypertension in adults aged $\geq 18$ years was about $22 \%$ in 2014 . $^{15}$ The prevalence of hypertension was highest in Africa, at $30 \%$ for all adults combined. The lowest prevalence was in the region of the Americas, at $18 \%$. The prevalence of hypertension was $19.6 \%$ across the Chinese adult population in 2014. With a national representative sample of adults aged $\geq 18$ years in the general population of China, Wang et al reported an even higher adjusted prevalence rate of hypertension, at $29.6 \% .^{16}$

The study by Huang et $a l^{17}$ showed that in Shenzhen the rate of hypertension prevalence among male residents 20 to 80 years working at public institutions increased by $40 \%$ from $10.12 \%$ in 1998 to $14.37 \%$ in 2002 , while the rate stood at $\sim 8 \%$ among female individuals. The findings of the current study showed rates of hypertension prevalence for male and female participants were $19.7 \%$ and $15.7 \%$, respectively, which are higher than the rates in 2002, suggesting an increase in the prevalence of hypertension in Shenzhen, although age and gender standardisation was not made for comparisons. The increasing trend of hypertension prevalence is consistent with findings at the national level for China. In the China National Nutrition and Health Survey of 2002, the prevalence of hypertension was about $18 \%$ in the Chinese adult population. ${ }^{10}$ A recent estimate in 2014 showed that the prevalence of hypertension in Chinese adults aged 18 years or older was $19.6 \%{ }^{16}$ Our study did not provide direct evidence to explain the higher hypertension prevalence, but, according to the current literature, possible explanations could be the increased ageing population, expansion of western fast food, and unhealthy lifestyles. ${ }^{18}$

The results showed that one half of the hypertensive individuals in the surveyed population were undetected, half of those detected were untreated by medications, and in half of those hypertensive individuals receiving treatment, their blood pressure levels were not controlled. Our findings suggest that 'rule of halves' is applicable to Shenzhen. The rate of hypertension awareness $(48.8 \%)$ in the current study is similar to the findings in China and other countries, but the rate of pharmacological treatment $(51.4 \%)$ is lower in the current study, while the rate of hypertension control $(43.2 \%)$ is higher. The study by Wang et $a l^{16}$ analysed a national representative sample of 50171 subjects and found that the rates of hypertension awareness, pharmacological treatments, and control were $42.6 \%, 80.0 \%$, and $27.4 \%$, respectively. Another study by Li et al, which investigated awareness and treatment of hypertension in 115 rural and urban communities involving 45108 individuals, showed similar results-that is, $42.4 \%$ for the awareness rate, $82.7 \%$ for the pharmacological treatment rate, and $23.7 \%$ for the hypertension control rate. ${ }^{19}$ The PURE (Prospective Urban Rural Epidemiology) study adopted a cross-sectional survey to examine hypertension prevalence, awareness, treatment and control among 153996 adults aged 35 to 70 years recruited from 628 communities in three high-, 10 upper-middle- and lower-middle-, and four low-income countries. ${ }^{20}$ That study showed that $46.5 \%$ of participants were aware of their diagnosis, while the majority $(87.5 \%)$ of those aware were receiving pharmacological treatment. It also revealed that a minority of those receiving treatment were controlled $(32.5 \%)$. Our study suggests that the awareness of hypertension in Shenzhen has reached the level of high-income countries $(49.0 \%)$, but the pharmacological treatment is even lower than that of low-income countries $(77.7 \%)$.

The results showed that the rates of non-pharmacological treatments, including reduced salt intake and regular physical exercise, regular monitoring, and primary care management of hypertension were strikingly low, which suggests room for improvement for the better management of hypertension. International and local hypertension management guidelines recommend lifestyle modifications for the management of hypertension. ${ }^{21-23}$ These modifications have been proven to reduce blood pressure, although their direct impact on morbidity and mortality is not known yet. Regular monitoring of blood pressure was found to be effective in improving patients' compliance to treatment and control of their hypertension..$^{24}$ Xiao et $a l^{25}$ integrated regular telephone follow-up into a community nursing intervention programme and found that it could significantly improve patients' adherence to antihypertensive therapies, and led to improved blood pressure control. Studies have shown that the management of hypertension in primary care settings can achieve better blood pressure control. The study by Li $e t a l^{26}$ showed that about $80 \%$ of hypertensive patients under primary care management had their blood pressure under control. A British study also revealed that the blood pressures of about $69 \%$ of registered hypertensive patients were under control. ${ }^{27}$

The results identified gaps between male and female participants, as well as between local and migrant participants, with respect to rates of hypertension prevalence, awareness, treatment and control. We found that women had higher rates of pharmacological treatments and 
control, but lower rates of prevalence, awareness and regular physical exercise when compared with men. Our findings are consistent with those of previous studies worldwide as well as in China in general. The study by Chow et $a l^{20}$ showed that among a multinational study population, female individuals consistently had greater awareness of their hypertension and higher rates of treatment and control than their male counterparts. The study by Wang et $a l^{16}$ also revealed that awareness, treatment and control rates were higher among female hypertensive individuals compared with males, but the prevalence was higher among men than among women. The migrant hypertensive individuals in the current study were more likely than their local counterparts to be aware of their condition, and to undertake non-pharmacological treatments and regular monitoring. In China, residents 35 years or older are recommended to undergo blood pressure measurement for hypertension detection when seeking healthcare from primary care facilities. The Medical Insurance Scheme for Migrant Employees puts emphasis on the primary level of care, with referral to higher levels only when justified by need. This may partly explain the greater awareness among migrants about hypertension compared with their local counterparts.

This is a representative study with 1767 samples to investigate the epidemiology of hypertension in Shenzhen, China. A high response rate was achieved. A rigorous random sampling approach was adopted and implemented. Standard protocols and instruments were employed for blood pressure measurement. We followed the most commonly used international definition of prevalence, awareness, treatment and control of hypertension to facilitate compatibility with the international literature. Data were collected by extensively trained interviewers and supervised by a vigorous quality assurance programme. However, the limitations should be addressed. First, selection bias might have been introduced by not having the characteristics of the non-respondents, although the response rate was high. Second, provision of data on awareness, pharmacological and non-pharmacological treatments, and primary care management relied on self-report. We were not able to construct a criterion standard for rigid validation. Third, the diagnosis of hypertension was based on a single visit involving blood pressure measurements and history recall. Fourth, we did not provide age and gender standardised estimates of prevalence, awareness, treatment and control of hypertension due to the unavailability of such information in the overall Shenzhen population with respect to age and gender distribution. Therefore, caution should be made when extrapolating the findings. Fifth, when recruiting participants, the eligibility criteria may have led to an overestimated participation rate. Sixth, other risk factors for CVD such as smoking status and overweight/obesity were not coded in the current study. Last but not least, the cross-sectional nature of the current study does not allow us to establish causal effect relationships.
This cross-sectional study found that the prevalence of hypertension was $17.6 \%$ in Shenzhen. Around $48.8 \%$ of participants with hypertension were aware of the diagnosis, while $51.4 \%$ of those who were aware were receiving pharmacological treatments. Among those hypertensives receiving pharmacological therapy, $43.2 \%$ had their blood pressure under control. Our findings suggest that population-based interventions such as establishing and screening health records and free health examinations may need to be implemented rigorously for the prevention and detection of hypertension. The availability and affordability of, and compliance with, medications need to be considered when formulating strategies to improve pharmacological treatments. Hypertensive individuals undertaking non-pharmacological treatments, regular monitoring and primary care management were few, which has major financial and social implications for policymakers. Given the increasing availability of primary care, strategies need to be developed to improve the effective primary care management of hypertension. Significant gaps were identified between women and men, and between the locals and migrants, regarding the prevalence, awareness, treatment and control of hypertension. This suggests a need to develop gender and household register tailored strategies for the prevention, detection, treatment and control of hypertension.

Correction notice This paper has been amended since it was published Online First. Owing to a scripting error, some of the publisher names in the references were replaced with 'BMJ Publishing Group'. This only affected the full text version, not the PDF. We have since corrected theseerrors and the correct publishers have been inserted into the references.

Acknowledgement This study was supported by an operating grant from the Shenzhen Government and the Shenzhen Basic Research Programme (grant number: JCYJ20160427183317387). However, the funding body had no role in the research design, data collection, interpretation of the data, and writing or submission of the manuscript. The authors would like to thank all the participants and staff who contributed the data for this study.

Contributors HTL and XFY conceived of the study, and took part in its design. HTL, XFY and XTD drafted the manuscript and were responsible for data interpretation. LZY, SJZ and JFZ participated in the data collection and analysis. YL and SJC helped to draft the manuscript and revised the draft for intellectual content. All authors have read and approved the final manuscript.

Competing interests None declared.

Patient consent Obtained.

Ethics approval This study was approved by the Longhua District Center for Chronic Disease Prevention and Control Ethics Committee.

Provenance and peer review Not commissioned; externally peer reviewed. Data sharing statement No additional unpublished data are available.

Open Access This is an Open Access article distributed in accordance with the Creative Commons Attribution Non Commercial (CC BY-NC 4.0) license, which permits others to distribute, remix, adapt, build upon this work non-commercially, and license their derivative works on different terms, provided the original work is properly cited and the use is non-commercial. See: http://creativecommons.org/licenses/by-nc/4.0/

(C) Article author(s) (or their employer(s) unless otherwise stated in the text of the article) 2017. All rights reserved. No commercial use is permitted unless otherwise expressly granted.

\section{REFERENCES}

1. Mortality GBD. GBD 2013 Mortality and Causes of Death Collaborators. Global, regional, and national age-sex specific 
all-cause and cause-specific mortality for 240 causes of death, 19902013: a systematic analysis for the global burden of disease study 2013. Lancet 2015;385:117-71.

2. The World Bank. Toward a healthy and haarmonious life in China: stemming the rising tide of non-communicable diseases. Washington DC: The World Bank, 2011.

3. Moran A, Gu D, Zhao D, et al. Future cardiovascular disease in China: Markov model and risk factor scenario projections from the coronary heart disease policy model-China. Circ Cardiovasc Qual Outcomes 2010;3:243-52

4. Lewington S, Clarke R, Qizilbash N, et al. Age-specific relevance of usual blood pressure to vascular mortality: a meta-analysis of individual data for one million adults in 61 prospective studies. Lancet 2002;360:1903-13.

5. World Health Organization. World Health Statistics. Geneva, 2012.

6. Kearney PM, Whelton M, Reynolds K, et al. Global burden of hypertension: analysis of worldwide data. Lancet 2005;365:217-23.

7. Huang J. The summary report of the National Symposium on Heart and vascular disease. Beijing, China: People's Publishing House, 1960.

8. Zhou H. Study on evaluation index system and method for comprehensive prevention and control community based for hypertension: Huazhong Technology University, 2004.

9. Wu X, Duan X, Gu D, et al. Prevalence of hypertension and its trends in Chinese populations. Int J Cardiol 1995;52:39-44.

10. Wu Y, Huxley R, Li L, et al. Prevalence, awareness, treatment, and control of hypertension in China: data from the China National Nutrition and Health Survey 2002. Circulation 2008;118:2679-86.

11. Bureau SS. NBS Survey Office in Shenzhen. Shenzhen Statistical Yearbook 2015. Beijing: China Statistics Press, 2015.

12. Committee $\mathrm{C}$. National guidelines for blood pressure measurement Chinese Journal of Hypertension 2011;19:1101-3.

13. Li H, Chung RY, Wei X, et al. Comparison of perceived quality amongst migrant and local patients using primary health care delivered by community health centres in Shenzhen, China. BMC Fam Pract 2014:15:76.

14. Bureau SS. Yearbook of Shenzhen Statistics. Beijing 2011.

15. WorldHealth Organization(WHO). Global status report on noncommunicable diseases 2014. Geneva, Switzerland, 2014.

16. Wang J, Zhang L, Wang F, et al. China National Survey of chronic kidney disease working Group. Prevalence, awareness, treatment, and control of hypertension in China: results from a national survey. Am J Hypertens 2014;27:1355-61.

17. Huang $\mathrm{C}$, Mai $\mathrm{H}$, Zhang L, et al. [The trend of hypertension in the past five years among the civil servants in Shenzhen]. Chinese Journal of Clinical Healthcare 2004;7:166-8.

18. Van de Poel E, O'Donnell O, Van Doorslaer E. Urbanization and the spread of diseases of affluence in China. Econ Hum Biol 2009;7:200-16.

19. Li W, Gu H, Teo KK, et al. PURE China Investigators. Hypertension prevalence, awareness, treatment, and control in 115 rural and urban communities involving 47000 people from China. J Hypertens 2016;34:39-46

20. Chow CK, Teo KK, Rangarajan S, et al. Prevalence, awareness, treatment, and control of hypertension in rural and urban communities in high-, middle-, and low-income countries. JAMA 2013;310:959-68.

21. Chobanian AV, Bakris GL, Black HR, et al. National Heart, Lung, and Blood Institute Joint National Committee on Prevention, Detection, Evaluation, and Treatment of High Blood Pressure, National High Blood Pressure Education Program Coordinating Committee. The Seventh Report of the Joint National Committee on prevention, detection, evaluation, and treatment of high blood pressure: the JNC 7 report. JAMA 2003;289:2560-72.

22. Liu LS. Writing group of Chinese guidelines for the management of hypertension. [2010 Chinese guidelines for the management of hypertension]. Zhonghua xin xue guan bing za zhi 2011;39:579-615.

23. National Institute for Health and Clinical Excellence. Hypertension: clinical management of primary hypertension in adults, 2011.

24. Xiao D, Zhong H, Qi X, et al. [Study on community intervention to the drug administration behavior for general hypertensive patients]. Modern Rehabilitation 2000;13:16-17.

25. Xiao C. [Study on the influence of community nursing intervention to treatment compliance of hypertensive patients]. Medical Journal of Qilu 2004:19:429-30.

26. Li $\mathrm{H}$, Wei $\mathrm{X}$, Wong $\mathrm{MC}$, et al. A comparison of the quality of hypertension management in primary care between Shanghai and Shenzhen: a cohort study of 3196 patients. Medicine 2015;94:e455

27. Hammouche S, Holland R, Steel N. Does quality of care for hypertension in primary care vary with postcode area deprivation? An observational study. BMC Health Serv Res 2011;11:297. 